OPEN ACCESS

Edited by:

Rebecca Ann Wingert, University of Notre Dame,

United States

Reviewed by:

Xinyu Weng,

Fudan University, China

Haobo Li,

Harvard Medical School,

United States

*Correspondence:

Ziyu Zhang

airity@163.com

Xiangshan Fan

fxs23@hotmail.com

Specialty section:

This article was submitted to

Molecular Medicine,

a section of the journal

Frontiers in Cell and Developmental

Biology

Received: 13 October 2020

Accepted: 26 February 2021

Published: 18 March 2021

Citation:

Dong W, Zhu Y, Zhang Y, Fan Z,

Zhang Z, Fan $X$ and Xu Y (2021)

BRG1 Links TLR4 Trans-Activation to LPS-Induced SREBP1a Expression

and Liver Injury.

Front. Cell Dev. Biol. 9:617073.

doi: 10.3389/fcell.2021.617073

\section{BRG1 Links TLR4 Trans-Activation to LPS-Induced SREBP1a Expression and Liver Injury}

\author{
Wenhui Dong', Yuwen Zhu'1, Yangxi Zhang', Zhiwen Fan'2, Ziyu Zhang ${ }^{3,4 *}$, \\ Xiangshan Fan ${ }^{2 *}$ and Yong $X u^{1,5}$
}

\begin{abstract}
${ }^{1}$ Key Laboratory of Targeted Invention of Cardiovascular Disease and Collaborative Innovation Center for Cardiovascular Translational Medicine, Department of Pathophysiology, Nanjing Medical University, Nanjing, China, ${ }^{2}$ Department of Pathology, Affiliated Nanjing Drum Tower Hospital of Nanjing University School of Medicine, Nanjing, China, ${ }^{3}$ Key Laboratory of Women's Reproductive Health of Jiangxi, Jiangxi Provincial Maternal and Child Health Hospital, Nanchang, China, ${ }^{4}$ Central Laboratory, Jiangxi Provincial Maternal and Child Health Hospital, Nanchang, China, ${ }^{5}$ Institute of Biomedical Research, Liaocheng University, Liaocheng, China
\end{abstract}

Multiple organ failure is one of the most severe consequences in patients with septic shock. Liver injury is frequently observed during this pathophysiological process. In the present study we investigated the contribution of Brahma related gene 1 (BRG1), a chromatin remodeling protein, to septic shock induced liver injury. When wild type (WT) and liver conditional BRG1 knockout (LKO) mice were injected with lipopolysaccharide (LPS), liver injury was appreciably attenuated in the LKO mice compared to the WT mice as evidenced by plasma ALT/AST levels, hepatic inflammation and apoptosis. Of interest, there was a down-regulation of sterol response element binding protein 1a (SREBP1a), known to promote liver injury, in the LKO livers compared to the WT livers. BRG1 did not directly bind to the SREBP1a promoter. Instead, BRG1 was recruited to the toll-like receptor 4 (TLR4) promoter and activated TLR4 transcription. Ectopic TLR4 restored SREBP1a expression in BRG1-null hepatocytes. Congruently, adenovirus carrying TLR4 or SREBP1a expression vector normalized liver injury in BRG1 LKO mice injected with LPS. Finally, a positive correlation between BRG1 and TLR4 expression was detected in human liver biopsy specimens. In conclusion, our data demonstrate that a BRG1-TLR4-SREBP1a axis that mediates LPS-induced liver injury in mice.

Keywords: liver injury, LPS, septic shock, transcriptional regulation, inflammation, apoptosis

\section{INTRODUCTION}

Septic shock, or septicemia, is a common pathophysiological process taking place in a wide range of occasions including infection, trauma, diabetes, and cirrhosis (Hotchkiss et al., 2016). Each year, incidents of septic shock trigger over 3,000,000 emergency visits and are associated with a $\sim 10 \%$ mortality rate in the United States alone (Wang et al., 2017). The most severe consequence of 
septic shock is the simultaneous dysfunction or failure of multiple organs (Azevedo et al., 2008). Liver dysfunction is common in patients with septic shock, which can be generally characterized as elevated plasma levels of alanine transaminase, alkaline phosphatase, and bilirubin (jaundice). Although liver failure is rare, liver injury significantly exacerbates the prognosis in patients with septic shock (Waseem et al., 2018).

The pathogenesis of liver dysfunction following septic shock is complex and not entirely clear at present. It is proposed that massive death of hepatocytes due to insufficient hepatic perfusion secondary to hypotension may be one of the major causes of sepsis-associated liver injury (Hotchkiss et al., 1999). Indeed, deletion of pro-apoptotic molecules such as JNK2 (Wang et al., 2006), perforin (Kuhla et al., 2009), and TNFR (Nowak et al., 2000), blocks apoptosis of hepatocytes and attenuates liver injury in mouse models of sepsis. Alternatively, altered inflammatory response is considered another critical contributing factor to sepsis-induced liver injury. It has been well-documented that enteric microbes and their components [e.g., lipopolysaccharide (LPS)] trans-located to the liver due to the disruption of the intestinal barrier function, combined with hepatic ischemia, illicit hepatic inflammation during sepsis (Yan and Li, 2014). A host of immune cells can be detected to infiltrate the liver following septic shock, including macrophages (Guillot and Tacke, 2019), T lymphocytes (Wesche-Soldato et al., 2007), myeloid-derived suppressor cells (Sander et al., 2010), and dentritic cells (Fan et al., 2015). It is generally agreed that excessively strong proinflammatory response precipitates liver injury in septic shock. For instance, depletion of the pro-inflammatory Kupffer cells by clodronate (Traeger et al., 2010) or NK cells by injection of anti-asialo GM1 antibodies suppresses hepatic inflammation and promotes survival in the septic mice. In addition, hepatocytespecific deletion or pharmaceutical inhibition of toll-like receptor 4 (TLR4), a master regulator of cellular inflammation to which LPS binds, attenuates liver injury following sepsis (Deng et al., 2013; Engelmann et al., 2020). How TLR4 expression is regulated in this process is not well understood.

Brahma related gene 1 (BRG1), is an epigenetic regulator of gene expression by functioning as the catalytic component of the mammalian SWI/SNF chromatin remodeling complex. BRG1 is universally expressed in various tissues and cells and is essential for organogenesis in mice (Bultman et al., 2000). BRG1 is dispensable for normal liver function in mice under physiological conditions (Li et al., 2018a,b). Recently, we have made several discoveries that portray BRG1 as a critical modulator of liver pathologies: mice with a selective deficiency of BRG1 in hepatocytes are protected from acetaminopheninduced acute liver failure and diet induced steatosis (Kong et al., 2018; Li et al., 2018a,b, 2019b,c; Fan et al., 2019, 2020; Liu et al., 2019a). Here we report that the BRG1 conditional knockout liver conditional BRG1 knockout (LKO) mice display an ameliorated phenotype of liver injury induced by septic shock. Mechanistically, BRG1 directly binds to the TLR4 promoter to activate TLR4 transcription leading to increased expression of SREBP1a, a key regulator of inflammation and apoptosis. Therefore, our data reinforce the notion that targeting BRG1 bring may be associated with benefits in liver injury.

\section{MATERIALS AND METHODS}

\section{Animals}

All animal experiments were reviewed and approved by the intramural Ethics Committee on Humane Treatment of Experimental Animals. Smarca $4^{f / f}$ mice (Dong et al., 2020) were crossed to Alb-Cre mice (Fan et al., 2020) to generate LKO mice. The mice were maintained under the SPF environment with $12 \mathrm{~h}$ light/dark cycles and libitum access to food and water. Liver injury was induced in male, 8-week old BRG1 conditional knockout (LKO) mice and wild type (WT) littermates by peritoneal injection of a single dose of LPS ( $15 \mathrm{mg} / \mathrm{kg}$, Sigma) as previously described (Liu et al., 2018). In certain experiments, the animals were injected via tail vein adenovirus carrying expression vectors for TLR4 or SREBP1a.

\section{Histology}

Histological analyses were performed essentially as described before (Li et al., 2019a). Briefly, the paraffin embedded sections were blocked with $10 \%$ normal goat serum for $1 \mathrm{~h}$ at room temperature and then incubated with an anti-F4/80 (Proteintech, 28463-1) antibody. Staining was visualized by incubation with anti-rabbit secondary antibody and developed with a streptavidin-horseradish peroxidase kit (Pierce) for $20 \mathrm{~min}$. Pictures were taken using an Olympus IX-70 microscope.

\section{Terminal Deoxynucleotidyltransferase dUTP Nick End Labeling Assay}

Terminal Deoxynucleotidyltransferase dUTP Nick End Labeling (TUNEL) assay was performed as previously described (Liu et al., 2019b; Zhao et al., 2019). Briefly, paraffin sections were incubated in the TUNEL reaction mixture (R\&D Systems, 4810-30-K) at $37^{\circ} \mathrm{C}$ for $60 \mathrm{~min}$. After several rinses with PBS, the sections were incubated with an anti-HRP antibody at room temperature for 30min. Pictures were taken using an Olympus IX-70 microscope.

\section{Cell Culture, Plasmids, and Transient Transfection}

Human hepatoma cells (HepG2) were maintained in DMEM supplemented with $10 \%$ fetal bovine serum (FBS, Hyclone). Primary hepatocytes were isolated and cultured as previously described (Fan et al., 2019). Small interfering RNAs targeting BRG1 are: \#1, AACATGCACCAGATGCACAAG and \#2, GCCCATGGAGTCCATGCAT. Transient transfections were performed with Lipofectamine 2000 (Invitrogen). $24 \mathrm{~h}$ after transfection, LPS $(1 \mathrm{mg} / \mathrm{ml})$ was added and incubated with the cells for additional $12 \mathrm{~h}$. Experiments were routinely performed in triplicate wells and repeated at least three times.

\section{Protein Extraction and Western Blot}

Whole cell lysates were obtained by re-suspending cell pellets in RIPA buffer (50 mM Tris pH7.4, $150 \mathrm{mMNaCl}, 1 \%$ Triton X100 ) with freshly added protease inhibitor (Roche) as previously described (Lu et al., 2019; Yang et al., 2019a,b; Mao et al., 2020). Western blot analyses were performed with anti-BRG1 (Santa Cruz, sc-10768), anti-SREBP1 (Proteintech, 14088-1), 
anti-TLR4 (Proteintech, 19811-1), and anti- $\beta$-actin (Sigma, A2228) antibodies.

\section{RNA Isolation and Real-Time PCR}

RNA was extracted with the RNeasy RNA isolation kit (Qiagen). Reverse transcriptase reactions were performed using a SuperScript First-strand Synthesis System (Invitrogen) as previously described (Liu et al., 2019b; Zhao et al., 2019). Real-time PCR reactions were performed on an ABI Prism 7,500 system with the following primers: human TLR4, 5'-CCCTGAGGCATTTAGGCAGCTA-3' and 5'-AGGTAGAGAGGTGGCTTAGGCT-3'; human BRG1, 5'TCATGTTGGCGAGCTATTTCC- $3^{\prime}$ and $5^{\prime}$-GGTTCCGAAGT CTCAACGATG-3'; human SREBP1a, 5'-CGGCGCTGCTG ACCGACATC- $3^{\prime}$ and $5^{\prime}$-CCCTGCCCCACTCCCAGCAT- $3^{\prime}$; mouse Tlr4, $5^{\prime}$-CAAGGGATAAGAACGCTGAGA-3' and 5'-GCAATGTCTCTGGCAGGTGTA-3'; mouse Srebp1a, 5'ATGGACGAGCTGGCCTTCGGTGAGGCGGC- $3^{\prime}$ and $5^{\prime}$-CA GGAAGGCTTCCAGAGAGGA-3'; mouse $I l 1 b, 5^{\prime}$-TGGACCT TCCAGGATGAGGACA- $3^{\prime}$ and $5^{\prime}$-GTTCATCTCGGAGCC TGTAGTG-3'; mouse Il6, $5^{\prime}$-TACCACTTCACAAGTCGGA GGC- $3^{\prime}$ and $5^{\prime}$-CTGCAAGTGCATCATCGTTGTTC- ${ }^{\prime}$; mouse Tnfa, $5^{\prime}$-GGTGCCTATGTCTCAGCCTCT- $3^{\prime}$ and $5^{\prime}$-CATC GGCTGGCACCACTAGTT-3'; mouse Bax, 5'-CGGCGAA TTGGAGATGAACTG- $3^{\prime}$ and $5^{\prime}$-GCAAAGTAGAAGAGGG CAACC-3'; mouse Bim, 5'-CGACAGTCTCAGGAGGAACC$3^{\prime}$ and $5^{\prime}$-CCTTCTCCATACCAGACGGA-3'; mouse Noxa, $5^{\prime}$-TCAGGAAGATCGGAGACAAA- $3^{\prime}$ and 5'-TGAGCA CACTCGTCCTTCAA-3'. Ct values of target genes were normalized to the $\mathrm{Ct}$ values of housekeekping control gene $\left(18 \mathrm{~s}, \quad 5^{\prime}\right.$-CGCGGTTCTATTTTGTTGGT- $3^{\prime}$ and $5^{\prime}$ TCGTCTTCGAAACTCCGACT- $3^{\prime}$ for both human and mouse genes) using the $\Delta \Delta \mathrm{Ct}$ method and expressed as relative mRNA expression levels compared to the control group which is arbitrarily set as 1 .

\section{Chromatin Immunoprecipitation}

Chromatin immunoprecipitation (ChIP) assays were performed essentially as described before (Chen et al., 2020a,b,c; Dong et al., 2020; Fan et al., 2020; Li et al., 2020a,b,c; Lv et al., 2020; Mao et al., 2020; Sun et al., 2020; Wu et al., 2020; Yang et al., 2020). In brief, chromatin in control and treated cells were crosslinked with $1 \%$ formaldehyde. Cells were incubated in lysis buffer (150 mMNaCl, $25 \mathrm{mM}$ Tris pH 7.5, 1\% Triton X-100, 0.1\% SDS, $0.5 \%$ deoxycholate) supplemented with protease inhibitor tablet and PMSF. DNA was fragmented into $\sim 200 \mathrm{bp}$ pieces using a Branson 250 sonicator. Aliquots of lysates containing $200 \mu \mathrm{g}$ of protein were used for each immunoprecipitation reaction with anti-BRG1 (Santa Cruz, sc-10768), anti-NF-кB (Santa Cruz, sc-372), anti-Sp1 (Abcam, ab227383), or pre-immune IgG.

\section{Human Specimen Collection}

Liver biopsies were collected from patients with acute liver injury (ALI) referring to Nanjing Drum Tower Hospital. Control liver samples were collected from donors whose livers were deemed unsuitable for transplantation. Written informed consent was obtained from subjects or families of liver donors. All procedures that involved human samples were approved by the Ethics Committee of Nanjing Drum Tower Hospital and adhered to the principles outlined in the Declaration of Helsinki.

\section{Statistical Analysis}

One-way ANOVA with post hoc Scheffe analyses were performed by SPSS software (IBM SPSS v18.0, Chicago, IL, United States). Unless otherwise specified, values of $p<0.05$ were considered statistically significant.

\section{RESULTS}

\section{BRG1 Deficiency in Hepatocyte Alleviates LPS-Induced Liver Injury}

We first evaluated the effect of BRG1 deletion in hepatocyte on LPS-induced liver injury. To this end, the BRG1 LKO mice and the WT mice were injected peritoneally with LPS and sacrificed $24 \mathrm{~h}$ after the injection. Quantification of plasma ALT levels (Figure 1A) and plasma AST levels (Figure 1B) showed that liver injury was attenuated in the LKO mice compared to the WT mice. Immunohistochemical staining with an anti-F4/80 antibody showed that there were fewer infiltrated macrophages in the LKO livers than in the WT livers (Figure 1C). The LKO mice also exhibited reduced apoptosis of hepatocytes as assessed by TUNEL staining (Figure 1D). Quantitative PCR results showed that the expression levels of several pro-inflammatory mediators, including $I l-1 b, I l-6$, and Tnf-a, as well as several pro-apoptotic molecules, including Bax, Bim, and Noxa, were down-regulated in the LKO livers compared to the WT livers (Figure 1E).

\section{BRG1 Deficiency Attenuates LPS-Induced SREBP1a Expression in vivo and in vitro}

Recent investigations have implicates SREBP family of proteins in the regulation of LPS-induced inflammatory response ( $\mathrm{Im}$ et al., 2011; Lee et al., 2018). We hypothesized that BRG1 may contribute to LPS induced liver injury through modulating SREBP expression levels. As shown in Figures 2A,B, out of the three SREBP isoforms, SREBP1a levels were up-regulated in the liver following LPS injection whereas BRG1 deficiency dampened the induction of SREBP1a. Neither SREBP1c nor SREBP2 was influenced by LPS injection or BRG1 deficiency. In cultured hepatocytes (HepG2), BRG1 knockdown by two different pairs of siRNAs suppressed the induction of SREBP1 a by LPS treatment at mRNA (Figure 2C) and protein (Figure 2D) levels. In addition, primary hepatocytes isolated from the WT mice responded better to LPS treatment than those from the BRG1 LKO mice by activating more SREBP1a molecules (Figures 2E,F).

\section{BRG1 Contributes to SREBP1a Induction by LPS via TLR4}

Previous studies have identified the presence of several conserved motifs for sequence-specific transcription factors, including Sp1 and NF-кB (Zhang et al., 2005), on the proximal SREBP1a promoter (Figure 3A, upper panel). ChIP assay confirmed that 

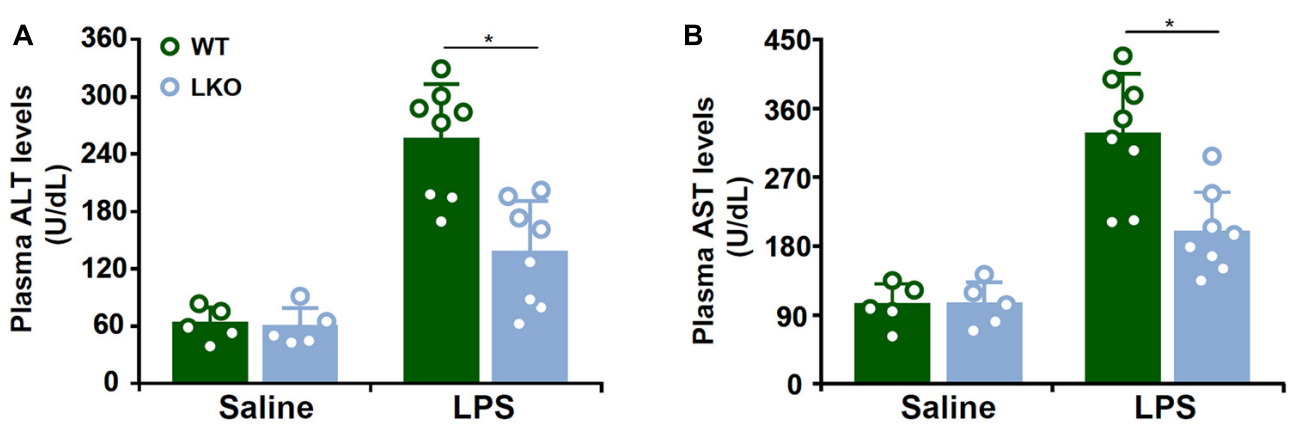

C
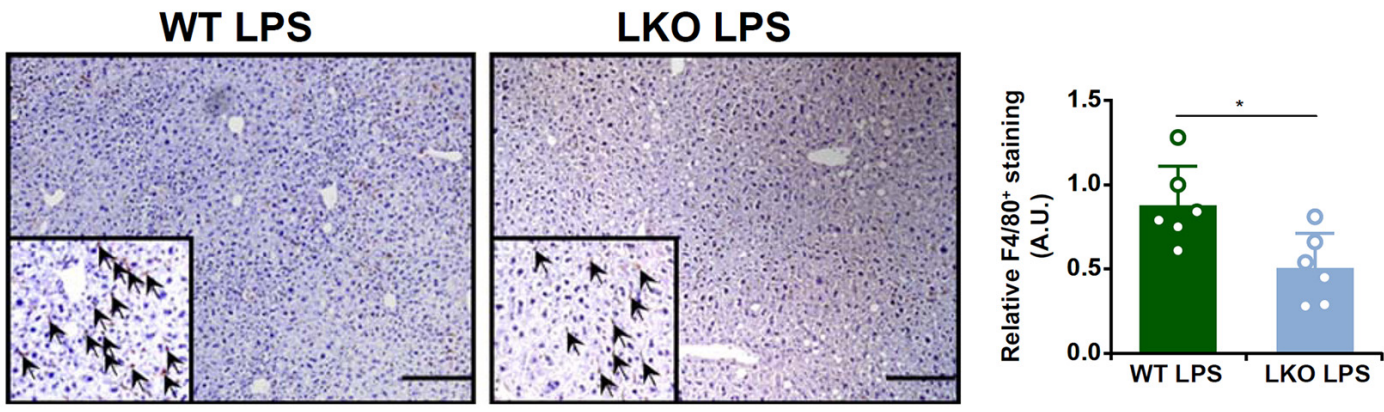

D
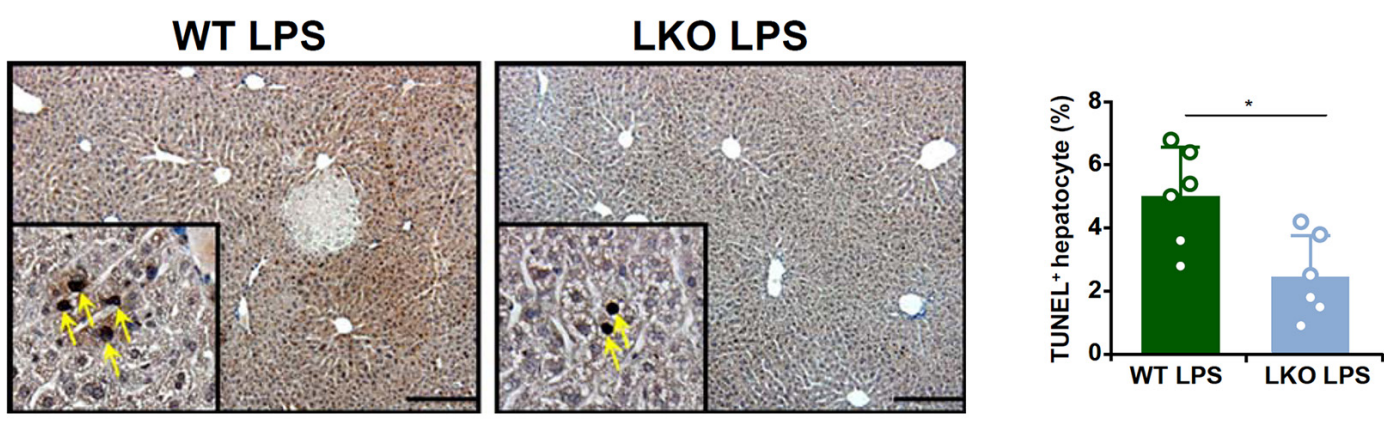

E

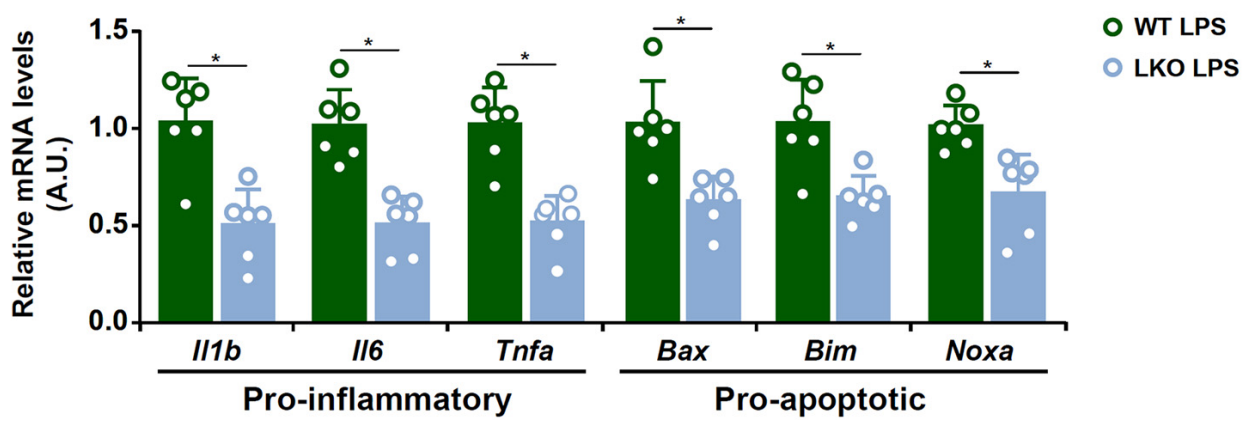

FIGURE 1 | BRG1 deficiency in hepatocyte alleviates LPS-induced liver injury. WT and BRG1 LKO mice were injected peritoneally with LPS (15 mg/kg) and sacrificed $24 \mathrm{~h}$ after the injection. (A) Plasma ALT levels. $N=5$ mice for the saline groups and $N=8$ mice for the LPS groups. (B) Plasma AST levels. $N=5$ mice for the saline groups and $N=8$ mice for the LPS groups. (C) Paraffin sections were stained with F4/80. $N=6$ mice for each group. (D) Paraffin sections were stained with TUNEL. $N=6$ mice for each group. (E) Gene expression levels were examined by qPCR. $N=6$ mice for each group. 

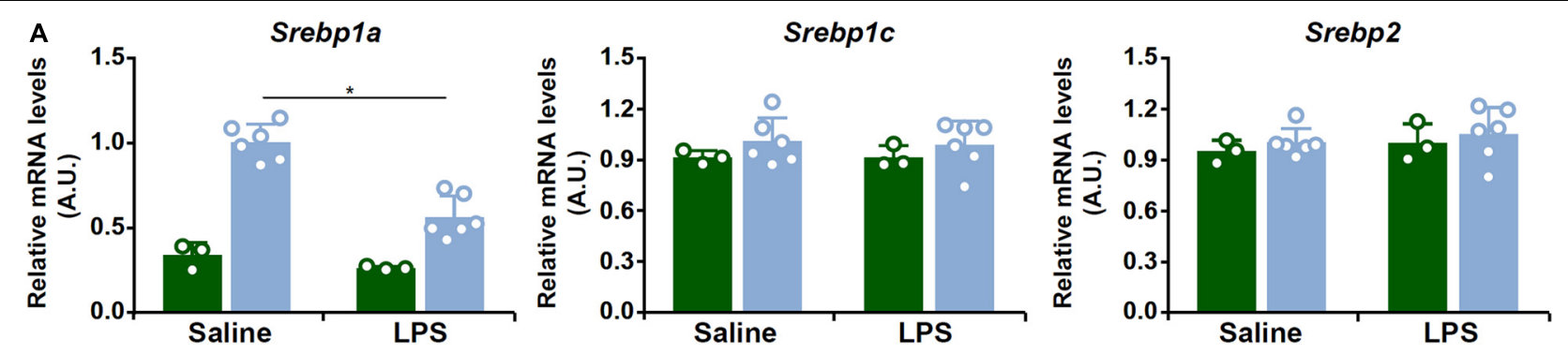

B

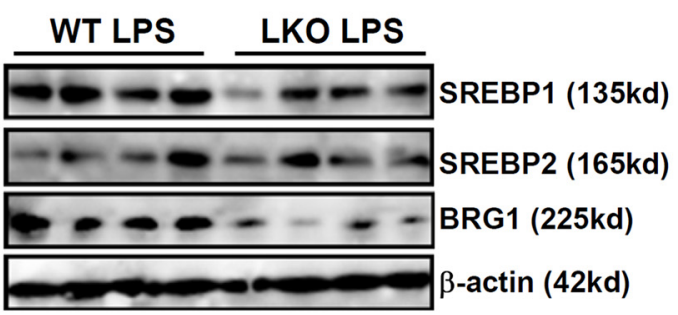

C

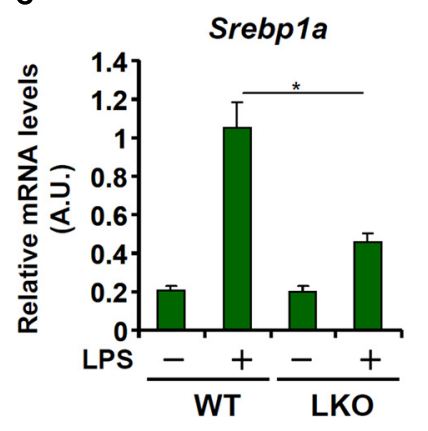

E

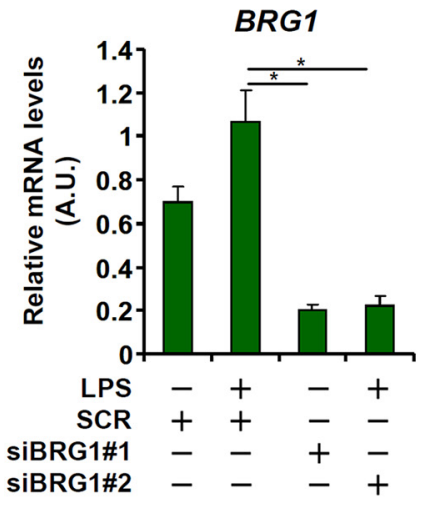

D

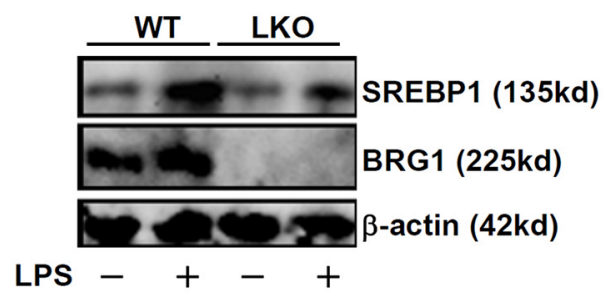

F

FIGURE 2 | BRG1 deficiency attenuates LPS-induced SREBP1a expression in vivo and in vitro. (A,B) WT and BRG1 LKO mice were injected peritoneally with LPS $(15 \mathrm{mg} / \mathrm{kg})$ and sacrificed $24 \mathrm{~h}$ after the injection. SREBP expression levels were examined by qPCR and Western. $N=3 \mathrm{mice}$ for the saline groups and $N=6 \mathrm{mice}$ for the LPS groups. (C,D) Primary hepatocytes isolated from WT and BRG1 LKO mice were exposed to LPS (1 $\mu \mathrm{g} / \mathrm{ml})$ for $12 \mathrm{~h}$ and SREBP1a expression was examined by qPCR and Western. (E,F) HepG2 cells were transfected with siRNA targeting BRG1 or scrambled siRNA (SCR) followed by treatment with LPS $(1 \mu \mathrm{g} / \mathrm{ml})$ for $12 \mathrm{~h}$ and SREBP1a expression was examined by qPCR and Western. 

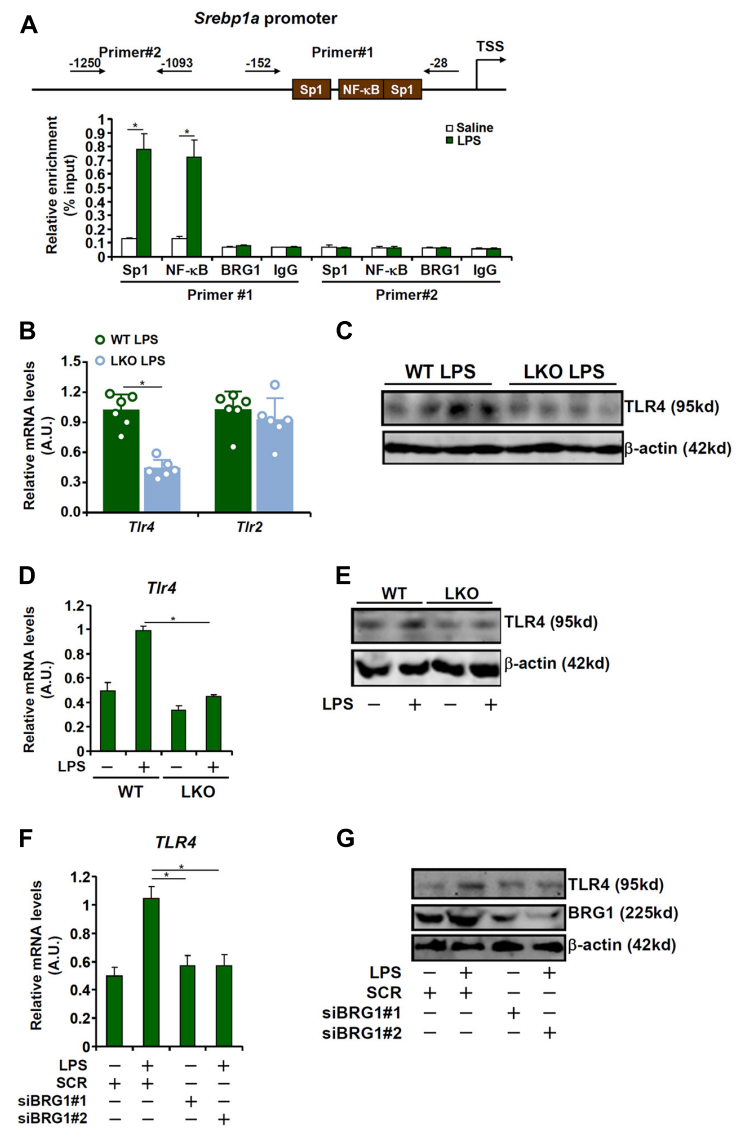

LPS -+-

G

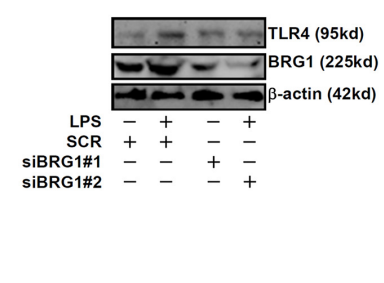

H

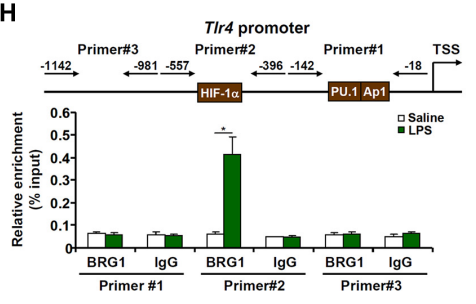

FIGURE 3 | BRG1 contributes to SREBP1a induction by LPS via TLR4. (A) Primary murine hepatocytes were treated with or without LPS (1 $\mu \mathrm{g} / \mathrm{ml})$ for $12 \mathrm{~h}$. ChIP assays were performed with anti-Sp1, anti-NF-kB, anti-BRG1, or IgG. (B,C) WT and BRG1 LKO mice were injected peritoneally with LPS $(15 \mathrm{mg} / \mathrm{kg})$ and sacrificed $24 \mathrm{~h}$ after the injection. TLR expression level was examined by qPCR and Western. (D,E) Primary hepatocytes isolated from WT and BRG1 LKO mice were exposed to LPS (1 $\mu \mathrm{g} / \mathrm{ml})$ for $12 \mathrm{~h}$ and TLR4 expression was examined by qPCR and Western. (F,G) HepG2 cells were transfected with siRNA targeting BRG1 or scrambled siRNA (SCR) followed by treatment with LPS $(1 \mu \mathrm{g} / \mathrm{ml})$ for $12 \mathrm{~h}$ and TLR4 expression was examined by $\mathrm{qPCR}$ and Western. $\mathbf{( H )}$ Primary murine hepatocytes were treated with or without LPS $(1 \mu \mathrm{g} / \mathrm{ml})$ for $12 \mathrm{~h}$. ChIP assays were performed with anti-BRG1 or lgG.

in response to LPS stimulation, both $\mathrm{Sp} 1$ and NF-kB were recruited to the proximal, but not the distal, SREBP1a promoter (Figure 3A). Of interest, although BRG1 has been shown to interact with Sp1 (Li et al., 2019c) and NF-кB (Fang et al., 2013), no discernable BRG1 binding was detected on either the proximal or the distal SREBP1a promoter (Figure 3A), indicating that BRG1 may contribute to SREBP1a transcription indirectly.

LPS induced pro-inflammatory and pro-apoptotic signaling can be mediated through the TLR4 receptor (Park and Lee, 2013) and the TLR2 receptor (Good et al., 2012). QPCR (Figure 3B) and Western blotting (Figure 3C) showed that BRG1 deficiency down-regulated TLR4 expression but not TLR2 expression. Indeed, LPS induced TLR4 expression in primary hepatocytes isolated from the WT mice but not the BRG1 LKO mice (Figures 3D,E). Further, BRG1 depletion dampened TLR4 induction by LPS treatment in HepG2 cells (Figures 3F,G). We then hypothesized that BRG1 might directly bind to the TLR4 promoter to activate TLR4 transcription. ChIP assay (Figure $3 \mathbf{H}$ ) showed that LPS treatment promoted BRG1 recruitment to a region of the TLR4 promoter that contains a conserved HIF- $1 \alpha$ site, but not to a more proximal region of the TLR4 promoter that contains both a PU.1 site and an AP-1 site or to the more distal TLR4 promoter.

\section{TLR4 Over-Expression Rescues SREBP1a Induction by LPS in Hepatocytes}

Having demonstrated that BRG1 may regulate SREBP1a expression to mediate LPS-induced liver injury by directly activating TLR4 transcription, we asked whether TLR4 overexpression could overcome BRG1 deficiency to restore SREBP1a expression. Adenovirus carrying either TLR4 expression vector (Ad-TLR4) or a control vector (Ad-GFP) was used to infect primary hepatocytes isolated from the BRG1 LKO mice. As shown in Figures $\mathbf{4 A , B}$, Ad-TLR4 infection more than compensated the reduction of TLR4 expression in the LKO cells and brought the levels of SREBP1a expression to those observed in WT cells. Similarly, Ad-TLR4 infection in HepG2 cells offset the crippling effect of BRG1 depletion by maintaining SREBP1a expression (Figures 4C,D).

\section{TLR4 Over-Expression or SREBP1a Over-Expression Restores Liver Injury in BRG1 Deficient Mice}

Because attenuation of LPS-induced liver injury in the BRG1 LKO mice could be attributed to TLR4/SREBP1a downregulation, we tested the hypothesis that re-introduction of exogenous TLR4 or SREBP1a might enable LPS to induce the same magnitude of liver injury in these mice as opposed to the WT mice. Adenovirus carrying TLR4 expression vector or SREBP1a vector or control vector was injected into the mice via tail vein followed by LPS injection. As shown in Figure 5A, Ad-TLR4 infection restored the expression of both TLR4 and SREBP1a whereas Ad-SREBP1a infection restored SREBP1a expression without altering TLR4 expression in the LKO livers. Exogenous TLR4 or SREBP1a overcame the BRG1 deficiency in the LKO livers by restoring LPS-induced liver injury as shown by plasma ALT (Figure 5B) and AST (Figure 5C) levels, by TUNEL staining (Figure 5D), by F4/80 staining (Figure 5E), and by qPCR measurements of pro-inflammatory and pro-apoptotic gene expression (Figure 5F). When primary hepatocytes were 

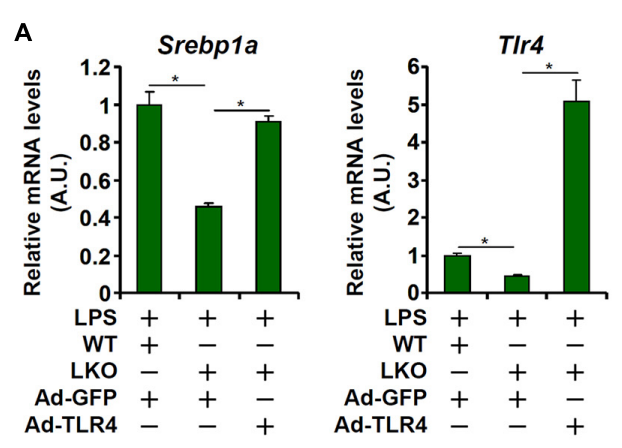

B

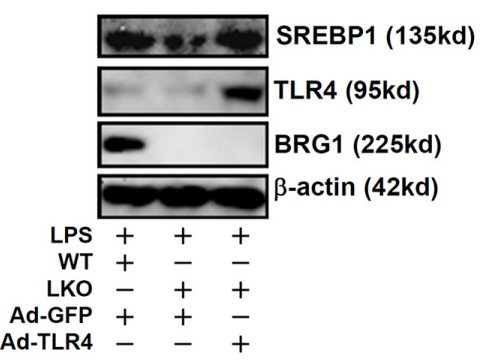

C
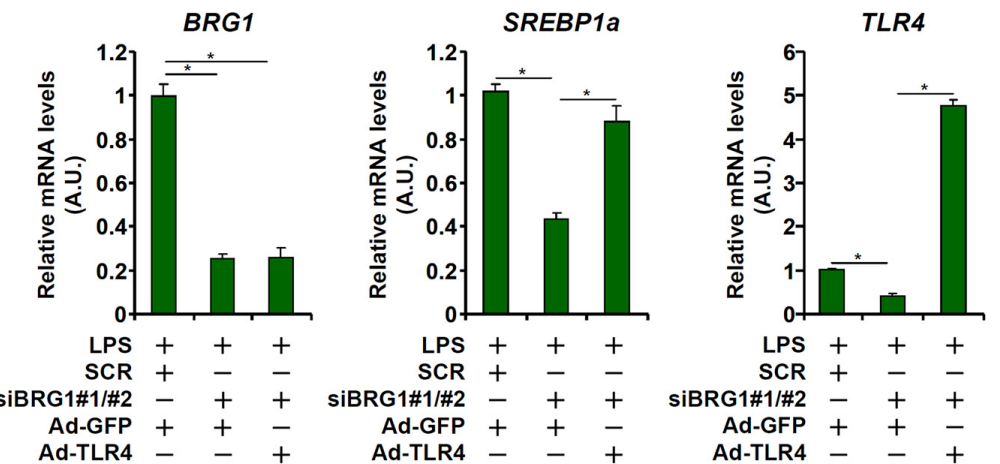

D

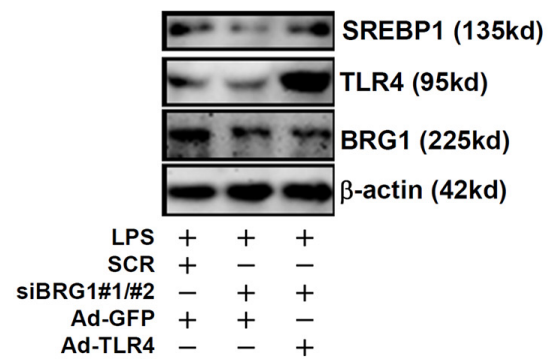

FIGURE 4 | TLR4 over-expression rescues SREBP1a induction by LPS in hepatocytes. (A,B) Primary hepatocytes isolated from WT and BRG1 LKO mice were infected with adenovirus carrying either TLR4 (Ad-TLR4) or GFP (Ad-GFP) followed by treatment with LPS $(1 \mu \mathrm{g} / \mathrm{ml})$ for $12 \mathrm{~h}$. SREBP1a expression was examined by qPCR and Western. (C,D) HepG2 cells were transfected with siRNA targeting BRG1 or scrambled siRNA (SCR) followed by infection with Ad-GFP-TLR4 or Ad-GFP and treatment with LPS $(1 \mathrm{\mu g} / \mathrm{ml})$ for $12 \mathrm{~h}$ and SREBP1a expression was examined by qPCR and Western.

freshly isolated from WT or LKO mice and transduced with adenovirus carrying TLR4 expression vector or SREBP1a vector or control vector followed by LPS treatment, it was observed that both TLR4 over-expression and SREBP1a over-expression were able to partially overcome BRG1 deficiency and normalize the levels of pro-inflammatory mediators and pro-apoptotic factors (Figure 5G).

\section{Correlation of BRG1 and TLR4 in Human Liver Biopsy Specimens}

Finally, we probed the relationship between BRG1 and TLR4 expression in human liver biopsy specimens. As shown in Figure 6A, immunohistochemical staining revealed that both
BRG1 levels and TLR4 levels were relatively low in the normal liver specimens but were markedly elevated in the specimens of ALI. Regression analysis showed a positive correlation between BRG1 and TLR4 expression (Figure 6B).

\section{DISCUSSION}

Septic shock represents a major cause for admissions into the intensive care unit (ICU) and the leading cause of deaths in non-coronary ICUs (Martin et al., 2003; Singer et al., 2016). Although septic shock causes the dysfunction of multiple organs, mortality rates of patients with liver failure tend to be the highest (Waseem et al., 2018). Therefore, effective interventional 
A

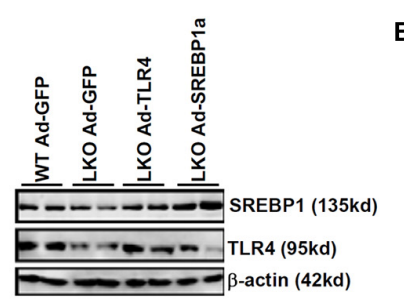

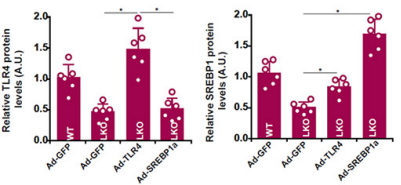

D

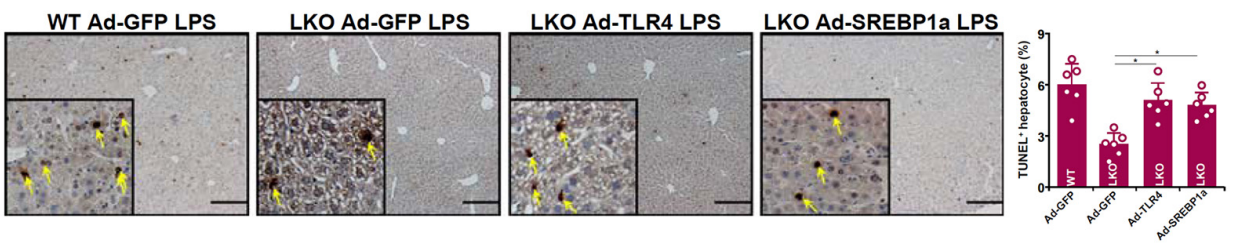

E
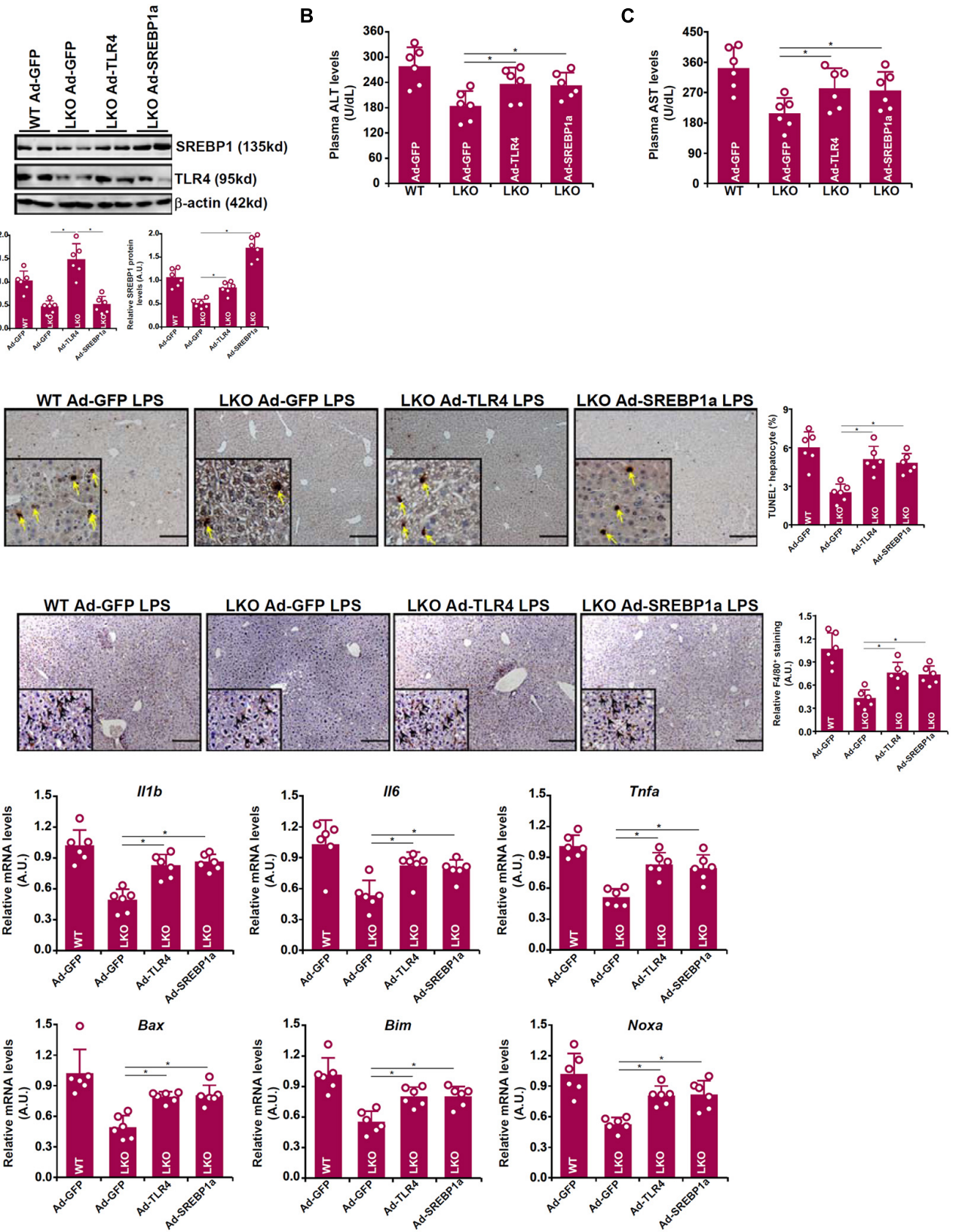

G

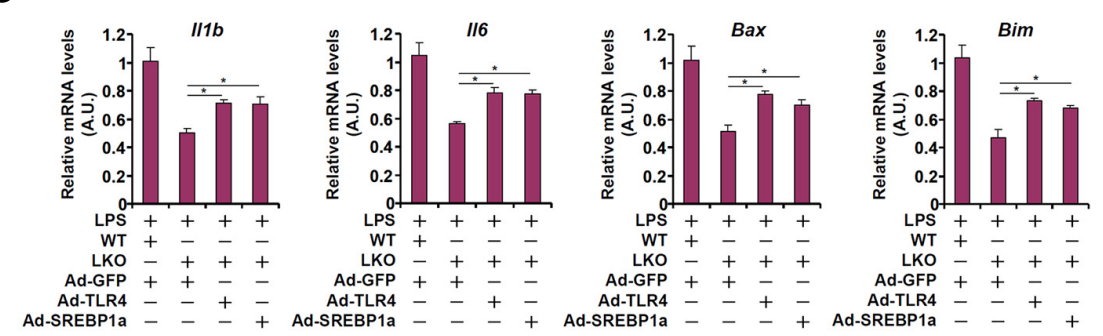

FIGURE 5 | TLR4 over-expression or SREBP1a over-expression restores liver injury in BRG1 deficient mice. (A-F) WT and BRG1 LKO mice were injected via tail veinadenovirus carrying either TLR4 (Ad-GFP-TLR4), SREBP1a (Ad-GFP-SREBP1a), or GFP (Ad-GFP). 2 week later, the mice were injected with injected peritoneally with LPS (15 mg/kg) and sacrificed $24 \mathrm{~h}$ after the injection. Gene expression levels were examined by Western (A). Plasma ALT levels (B). Plasma AST levels (C). Paraffin sections were stained with F4/80 (D). Paraffin sections were stained with TUNEL (E). Gene expression levels were examined by qPCR (F). $N=6$ mice for all groups. (G) Primary hepatocytes were isolated from WT or BRG1 LKO mice and transduced with indicated andenoviral particles. The cells were with LPS (1 $\mu \mathrm{g} / \mathrm{ml})$ for $12 \mathrm{~h}$ and gene expression was examined by qPCR. 


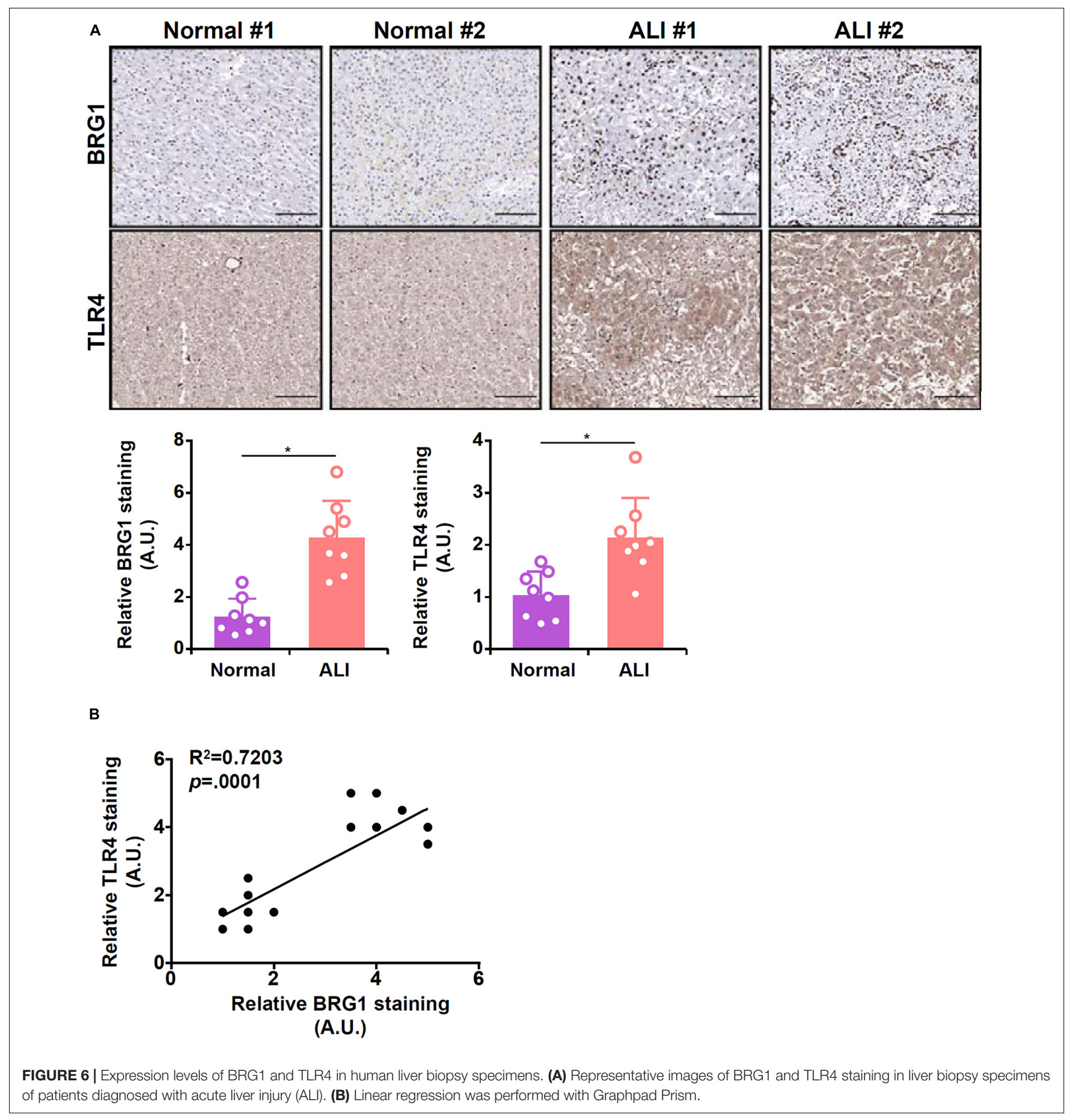

strategies that ameliorate liver dysfunction serve to boost the overall survival of patients with septic shock. Here we describe a novel transcriptional mechanism whereby the chromatin remodeling protein BRG1 contributes to liver injury in a mouse model of LPS-induced septic shock.

It has been previously shown that SREBP1a mediates the hepatic inflammatory response during septic shock (Im et al., 2011). Our data suggest that BRG1 deficiency leads to down-regulation of SREBP1a indirectly via TLR4.
Because TLR4 is positioned at the very top of LPS-provoked signaling, there certainly are other possibilities that should be considered when interpreting these data. Liu et al. have found a global decrease in NF- $\mathrm{B}$ activity in the TLR4-null hepatocytes compared to WT hepatocytes treated with LPS (Liu et al., 2002). BRG1 is a well-established co-factor for NF- $\kappa$ B (Fang et al., 2013; Zhang et al., 2019). Therefore it is possible that BRG1 may regulate liver injury by modulating NF- $\kappa$ B activity in hepatocytes. In addition, BRG1 is directly involved in the 
transcription of pro-inflammatory genes (Ramirez-Carrozzi et al., 2006) and pro-apoptotic genes (Napolitano et al., 2007). We have previously shown that BRG1 can interact with SREBP and facilitate SREBP-dependent transcriptional events related to lipogenesis and cholesterogenesis in hepatocytes (Li et al., 2018b; Fan et al., 2020). SREBP1 has been shown to directly bind to the promoter regions of pro-inflammatory genes (Oishi et al., 2017) and pro-apoptotic genes (Wang et al., 2005; Gibot et al., 2009), raising the intriguing possibility that BRG1 may co-occupy the gene promoters with SREBP1 and potentiate the transcriptional activity of SREPB1 to stimulate cellular inflammation and/or apoptosis. Finally, SREBP1 activity is not only determined by its overall expression but its liberation from the membrane and translocation into the nucleus (Horton et al., 2002). Diomede et al. have observed that LPS administration in mice promotes hepatic SREBP1 maturation in a TLR4-dependent manner (Diomede et al., 2001). Whether BRG1 can contribute to this process remains to be determined.

We show here that BRG1 is recruited to the Tlr4 promoter region containing a conserved hypoxia response element (HRE). Previously we have reported that BRG1 can interact with HIF$1 \alpha$ and mediate HIF- $1 \alpha$ induced transcription of IL-33 gene (Liu et al., 2019b), MRP8 gene (Li et al., 2020c), and KDM3A gene (Li et al., 2019d) respectively. These data appear to point to an interesting scenario wherein a HIF-1 $\alpha$-BRG1 complex regulates the hepatic transcriptome to promote liver dysfunction. Indeed, mice with hepatocyte-specific HIF-1 $\alpha$ deletion exhibit similar phenotypes as the BRG1 LKO mice in a number of different animal models of liver injury. For instance, the HIF$1 \alpha$ LKO mice are resistant to LPS-induced liver injury (Nath et al., 2011). Hepatocyte-specific HIF-1 $\alpha$ deficiency also protects the mice from obesity and steatosis (Lee et al., 2019) and liver necrosis caused by hepatotoxic substances (Sparkenbaugh et al., 2011; Roychowdhury et al., 2014). The genomewide mechanistic insights underlying the functional overlapping between HIF$1 \alpha$ and BRG1 are currently lacking. There are several reports demonstrating genomewide binding patterns of HIF-1 $\alpha$ (Schodel et al., 2011; Smythies et al., 2019) and BRG1 (Bossen et al., 2015; Barutcu et al., 2016; Raab et al., 2017) using ChIP-seq; none of these studies examined (primary) hepatocytes. Future studies should focus on deciphering whether the functional overlapping between HIF-1 $\alpha$ and BRG1 can be explained by shared transcriptional programs.

There are several major limitations regarding the approaches and conclusions of the present study. First, a string of recent studies have claimed that BRG1 possesses a protective role in hepatic ischemia-reperfusion injury (Ge et al., 2017a,b,c). The mechanism, accordingly to Ge et al., lies in the observation that BRG1 can interact with the anti-oxidative transcription factor $\mathrm{Nrf} 2$ to activate HO-1 transcription in hepatocytes, which may not be the rate-limiting process in LPS-induced liver injury as investigated in the present study. Alternatively, whereas a hepatocyte-specific BRG1 deletion mouse strain was used in the present study, Ge et al. in their series of investigations used a mouse strain harboring systemic BRG1 over-expression, which may engender non-hepatocyte autonomous effects. Second, a single mouse model (LPS injection) was harnessed to assess the role of BRG1 in ALI. Other models widely exploited by the field to study ALI include dual injection of LPS plus pyrazole (a CYP2E1 inducer), dual injection of LPS plus D-galactosamine, and the cecal ligation and puncture (CLP) procedure (Louis et al., 1997; Lu et al., 2005; Zhu et al., 2013). It would be of great help to ascertain the role of BRG1 in additional mouse models. Third, no transcriptomic analysis (e.g., RNA-seq) was performed to screen for genomewide targets downstream of BRG1 that might contribute to the observed phenotype. Wang et al. (2019) have compared the transcriptomes of WT livers and BRG1null livers following partial hepatectomy in mice by RNA-seq and found that the p53 pathway is preferentially activated by BRG1 deficiency. Because several studies have demonstrated a protective role for p53 in acute organ injuries (Liu et al., 2009; Sun et al., 2018), it is tempting to speculate that attenuation of liver injury by BRG1 deficiency might be attributed to a secondary up-regulation of p53. These issues certainly deserve further attention.

In summary, our data add another layer of evidence that supports BRG1 as a common mediator of liver injury. Smallmolecule BRG1 inhibitors have been designed and proven effective in the intervention of malignant cancers both in cell culture (Wu et al., 2016) and in animal models (Ding et al., 2019). It would be of great interest to determine whether these compounds can be considered as a reasonable approach to treat liver disorders.

\section{DATA AVAILABILITY STATEMENT}

The original contributions presented in the study are included in the article/supplementary material, further inquiries can be directed to the corresponding author/s.

\section{ETHICS STATEMENT}

The animal study was reviewed and approved by Nanjing Medical University Ethics Committee on Humane Treatment of Experimental Animals.

\section{AUTHOR CONTRIBUTIONS}

$\mathrm{XF}$ and $\mathrm{ZZ}$ conceived the project. WD, YwZ, YxZ, and ZF designed experiments, performed experiments, and collected, analyzed the data. XF and ZZ provided funding. YX wrote the manuscript. All authors contributed to the article and approved the submitted version.

\section{FUNDING}

This work was supported by from the National Natural Science Foundation of China (81771559 and 81700554), Key Research and Development Program of Jiangxi 
Province (20181BBG70009), from the Nanjing Municipal Administration of Health and Human Services (YKK17061), from the Fundamental Research Funds for Central

\section{REFERENCES}

Azevedo, L. C., Park, M., and Schettino, G. P. (2008). Novel potential therapies for septic shock. Shock 30(Suppl. 1), 60-66. doi: 10.1097/SHK.0b013e318181a425

Barutcu, A. R., Lajoie, B. R., Fritz, A. J., McCord, R. P., Nickerson, J. A., van Wijnen, A. J., et al. (2016). SMARCA4 regulates gene expression and higherorder chromatin structure in proliferating mammary epithelial cells. Genome Res. 26, 1188-1201. doi: 10.1101/gr.201624.115

Bossen, C., Murre, C. S., Chang, A. N., Mansson, R., Rodewald, H. R., and Murre, C. (2015). The chromatin remodeler Brgl activates enhancer repertoires to establish B cell identity and modulate cell growth. Nat. Immunol. 16, 775-784. doi: 10.1038/ni.3170

Bultman, S., Gebuhr, T., Yee, D., La Mantia, C., Nicholson, J., Gilliam, A., et al. (2000). A Brg1 null mutation in the mouse reveals functional differences among mammalian SWI/SNF complexes. Mol. Cell 6, 1287-1295.

Chen, B., Fan, Z., Sun, L., Chen, J., Feng, Y., Fan, X., et al. (2020a). Epigenetic activation of the small GTPase TCL contributes to colorectal cancer cell migration and invasion. Oncogenesis 9:86. doi: 10.1038/s41389-020-00269-9

Chen, B., Yuan, Y., Sun, L., Chen, J., Yang, M., Yin, Y., et al. (2020b). MKL1 mediates TGF- $\beta$ induced RhoJ transcription to promote breast cancer cell migration and invasion. Front. Cell Dev. Biol. 8:832. doi: 10.3389/fcell.2020. 00832

Chen, B., Zhao, Q., Xu, T., Yu, L., Zhuo, L., Yang, Y., et al. (2020c). BRG1 activates PR65A transcription to regulate NO bioavailability in vascular endothelial cell. Front. Cell Dev. Biol. 8:774. doi: 10.3389/fcell.2020.00774

Deng, M., Scott, M. J., Loughran, P., Gibson, G., Sodhi, C., Watkins, S., et al. (2013). Lipopolysaccharide clearance, bacterial clearance, and systemic inflammatory responses are regulated by cell type-specific functions of TLR4 during sepsis. J. Immunol. 190, 5152-5160. doi: 10.4049/jimmunol.1300496

Ding, Y., Li, N., Dong, B., Guo, W., Wei, H., Chen, Q., et al. (2019). Chromatin remodeling ATPase BRG1 and PTEN are synthetic lethal in prostate cancer. J. Clin. Invest. 129, 759-773. doi: 10.1172/JCI123557

Diomede, L., Albani, D., Bianchi, M., and Salmona, M. (2001). Endotoxin regulates the maturation of sterol regulatory element binding protein-1 through the induction of cytokines. Eur. Cytokine Netw. 12, 625-630.

Dong, W., Kong, M., Zhu, Y., Shao, Y., Wu, D., Lu, J., et al. (2020). Activation of TWIST transcription by chromatin remodeling protein BRG1 contributes to liver fibrosis in mice. Front. Cell Dev. Biol. 8:340. doi: $10.3389 /$ fcell.2020.00340

Engelmann, C., Sheikh, M., Sharma, S., Kondo, T., Loeffler-Wirth, H., Zheng, Y. B., et al. (2020). Toll-like receptor 4 is a therapeutic target for prevention and treatment of liver failure. J. Hepatol. 73, 102-112. doi: 10.1016/j.jhep.2020.01.011

Fan, X., Liu, Z., Jin, H., Yan, J., and Liang, H. P. (2015). Alterations of dendritic cells in sepsis: featured role in immunoparalysis. Biomed. Res. Int. 2015:903720. doi: $10.1155 / 2015 / 903720$

Fan, Z., Kong, M., Li, M., Hong, W., Fan, X., and Xu, Y. (2020). Brahma related gene 1 (Brg1) regulates cellular cholesterol synthesis by acting as a co-factor for SREBP2. Front. Cell Dev. Biol. 8:259. doi: 10.3389/fcell.2020.00259

Fan, Z., Li, N., Xu, Z., Wu, J., Fan, X., and Xu, Y. (2019). An interaction between MKL1, BRG1, and C/EBPbeta mediates palmitate induced CRP transcription in hepatocytes. Biochim. Biophys. Acta Gene Regul. Mech. 1862:194412. doi: 10.1016/j.bbagrm.2019.194412

Fang, F., Chen, D., Yu, L., Dai, X., Yang, Y., Tian, W., et al. (2013). Proinflammatory stimuli engage brahma related gene 1 and brahma in endothelial injury. Circ. Res. 113, 986-996. doi: 10.1161/CIRCRESAHA.113.301296

Ge, M., Chen, C., Yao, W., Zhou, S., Huang, F., Cai, J., et al. (2017a). Overexpression of Brg1 alleviates hepatic ischemia/reperfusion-induced acute lung injury through antioxidative stress effects. Oxid. Med. Cell. Longev. 2017:8787392. doi: $10.1155 / 2017 / 8787392$
Universities (021414380323), and from Nanjing Medical Science and Technology Development Foundation (QRX17004 and ZKX17013).
Ge, M., Chen, H., Zhu, Q., Cai, J., Chen, C., Yuan, D., et al. (2017b). Propofol post-conditioning alleviates hepatic ischaemia reperfusion injury via BRG1mediated Nrf2/HO-1 transcriptional activation in human and mice. J. Cell. Mol. Med. 21, 3693-3704. doi: 10.1111/jcmm.13279

Ge, M., Yao, W., Yuan, D., Zhou, S., Chen, X., Zhang, Y., et al. (2017c). Brg1-mediated Nrf2/HO-1 pathway activation alleviates hepatic ischemiareperfusion injury. Cell Death Dis. 8:e2841. doi: 10.1038/cddis.2017.236

Gibot, L., Follet, J., Metges, J. P., Auvray, P., Simon, B., Corcos, L., et al. (2009). Human caspase 7 is positively controlled by SREBP-1 and SREBP-2. Biochem. J. 420, 473-483. doi: 10.1042/BJ20082057

Good, D. W., George, T., and Watts, B. A. III (2012). Toll-like receptor 2 is required for LPS-induced Toll-like receptor 4 signaling and inhibition of ion transport in renal thick ascending limb. J. Biol. Chem. 287, 20208-20220. doi: 10.1074/jbc.M111.336255

Guillot, A., and Tacke, F. (2019). Liver macrophages: old dogmas and new insights. Hepatol. Commun. 3, 730-743. doi: 10.1002/hep4.1356

Horton, J. D., Goldstein, J. L., and Brown, M. S. (2002). SREBPs: transcriptional mediators of lipid homeostasis. Cold Spring Harb. Symp. Quant. Biol. 67, 491-498.

Hotchkiss, R. S., Moldawer, L. L., Opal, S. M., Reinhart, K., Turnbull, I. R., and Vincent, J. L. (2016). Sepsis and septic shock. Nat. Rev. Dis. Primers 2:16045. doi: 10.1038/nrdp.2016.45

Hotchkiss, R. S., Swanson, P. E., Freeman, B. D., Tinsley, K. W., Cobb, J. P., Matuschak, G. M., et al. (1999). Apoptotic cell death in patients with sepsis, shock, and multiple organ dysfunction. Crit. Care Med. 27, 1230-1251. doi: 10.1097/00003246-199907000-00002

Im, S. S., Yousef, L., Blaschitz, C., Liu, J. Z., Edwards, R. A., Young, S. G., et al. (2011). Linking lipid metabolism to the innate immune response in macrophages through sterol regulatory element binding protein-1a. Cell Metab. 13, 540-549. doi: 10.1016/j.cmet.2011.04.001

Kong, M., Chen, X., Xu, H., Wenping, Fang, M., and Xu, Y. (2018). Hepatocytespecific deletion of Brg1 alleviates methionine-and-choline-deficient diet (MCD) induced non-alcoholic steatohepatitis in mice. Biochem. Biophys. Res. Commun. 503, 344-351. doi: 10.1016/j.bbrc.2018.06.027

Kuhla, A., Eipel, C., Abshagen, K., Siebert, N., Menger, M. D., and Vollmar, B. (2009). Role of the perforin/granzyme cell death pathway in D-Gal/LPSinduced inflammatory liver injury. Am. J. Physiol. Gastrointest. Liver Physiol. 296, G1069-76. doi: 10.1152/ajpgi.90689.2008

Lee, J. H., Phelan, P., Shin, M., Oh, B. C., Han, X., Im, S. S., et al. (2018). SREBP-1astimulated lipid synthesis is required for macrophage phagocytosis downstream of TLR4-directed mTORC1. Proc. Natl. Acad. Sci. U.S.A. 115, E12228-E12234. doi: $10.1073 /$ pnas. 1813458115

Lee, Y. S., Riopel, M., Cabrales, P., and Bandyopadhyay, G. K. (2019). Hepatocytespecific HIF-1alpha ablation improves obesity-induced glucose intolerance by reducing first-pass GLP-1 degradation. Sci. Adv. 5:eaaw4176. doi: 10.1126/ sciadv.aaw4176

Li, N., Kong, M., Zeng, S., Xu, Z., Li, M., Hong, W., et al. (2018a). The chromatin remodeling protein BRG1 regulates APAP-induced liver injury by modulating CYP3A11 transcription in hepatocyte. Biochim. Biophys. Acta Mol. Basis Dis. 1864, 3487-3495.

Li, N., Li, M., Hong, W., Shao, J., Xu, H., Shimano, H., et al. (2018b). Brg1 regulates pro-lipogenic transcription by modulating SREBP activity in hepatocytes. Biochim. Biophys. Acta Mol. Basis Dis. 1864(9 Pt B), 2881-2889. doi: 10.1016/ j.bbadis.2018.05.022

Li, N., Liu, S., Zhang, Y., Yu, L., Hu, Y., Wu, T., et al. (2020a). Transcriptional activation of matricellular protein Spondin2 (SPON2) by BRG1 in vascular endothelial cells promotes macrophage chemotaxis. Front. Cell Dev. Biol. 8:794. doi: 10.3389/fcell.2020.00794

Li, Z., Chen, B., Dong, W., Kong, M., Fan, Z., Yu, L., et al. (2019a). MKL1 promotes endothelial-to-mesenchymal transition and liver fibrosis by activating TWIST1 transcription. Cell Death Dis. 10:899. doi: 10.1038/s41419-019-2101-4 
Li, Z., Chen, B., Dong, W., Kong, M., Shao, Y., Fan, Z., et al. (2019b). The chromatin remodeler Brg1 integrates ROS production and endothelial-mesenchymal transition to promote liver fibrosis in mice. Front. Dev. Cell Biol. 7:245. doi: 10.3389/fcell.2019.00245

Li, Z., Kong, X., Zhang, Y., Yu, L., Guo, J., and Xu, Y. (2020b). Dual roles of chromatin remodeling protein BRG1 in angiotensin II-induced endothelialmesenchymal transition. Cell Death Dis. 11:549. doi: 10.1038/s41419-02002744-y

Li, Z., Lv, F., Dai, C., Wang, Q., JIang, C., Fang, M., et al. (2019c). Activation of galectin-3 (LGALS3) transcription by injurious stimuli in the liver is commonly mediated by BRG1. Front. Cell Dev. Biol. 7:310. doi: 10.3389/fcell.2019.00310

Li, Z., Xia, J., Fang, M., and Xu, Y. (2019d). Epigenetic regulation of lung cancer cell proliferation and migration by the chromatin remodeling protein BRG1. Oncogenesis 8:66. doi: 10.1038/s41389-019-0174-7

Li, Z., Zhang, Y., Yu, L., Xiao, B., Li, T., Kong, X., et al. (2020c). BRG1 stimulates endothelial derived alarmin MRP8 to promote macrophage infiltration in an animal model of cardiac hypertrophy. Front. Cell Dev. Biol. 8:569. doi: 10.3389/ fcell.2020.00569

Liu, G., Park, Y. J., Tsuruta, Y., Lorne, E., and Abraham, E. (2009). p53 Attenuates lipopolysaccharide-induced NF-kappaB activation and acute lung injury. J. Immunol. 182, 5063-5071. doi: 10.4049/jimmunol.0803526

Liu, L., Hong, W., Li, M., Ren, H., Wang, J., Xu, H., et al. (2019a). A cross talk between BRG1 and males absent on the first contributes to reactive oxygen species production in a mouse model of nonalcoholic steatohepatitis. Antioxid. Redox. Signal. 30, 1539-1552. doi: 10.1089/ars.2016.6822

Liu, L., Mao, L., Wu, X., Wu, T., Liu, W., Yang, Y., et al. (2019b). BRG1 regulates endothelial-derived IL-33 to promote ischemia-reperfusion induced renal injury and fibrosis in mice. Biochim. Biophys. Acta Mol. Basis Dis. 1865, 2551-2561. doi: 10.1016/j.bbadis.2019.06.015

Liu, L., Wu, X., Xu, H., Yu, L., Zhang, X., Li, L., et al. (2018). Myocardinrelated transcription factor a (MRTF-A) contributes to acute kidney injury by regulating macrophage ROS production. Biochim. Biophys. Acta Mol. Basis Dis. 1864, 3109-3121. doi: 10.1016/j.bbadis.2018.05.026

Liu, S., Gallo, D. J., Green, A. M., Williams, D. L., Gong, X., Shapiro, R. A., et al. (2002). Role of toll-like receptors in changes in gene expression and NF-kappa $\mathrm{B}$ activation in mouse hepatocytes stimulated with lipopolysaccharide. Infect. Immun. 70, 3433-3442. doi: 10.1128/iai.70.7.3433-3442.2002

Louis, H., Le Moine, O., Peny, M. O., Gulbis, B., Nisol, F., Goldman, M., et al. (1997). Hepatoprotective role of interleukin 10 in galactosamine/lipopolysaccharide mouse liver injury. Gastroenterology 112, 935-942. doi: 10.1053/gast.1997.v112.pm9041256

Lu, Y., Lv, F., Kong, M., Chen, X., Duan, Y., Sun, D., et al. (2019). A cAbl-MRTF-A feedback loop contributes to hepatic stellate cell activation. Front. Cell Dev. Biol. 7:243. doi: $10.3389 / \mathrm{fcell} .2019 .00243$

Lu, Y., Wang, X., and Cederbaum, A. I. (2005). Lipopolysaccharide-induced liver injury in rats treated with the CYP2E1 inducer pyrazole. Am. J. Physiol. Gastrointest. Liver Physiol. 289, G308-G319. doi: 10.1152/ajpgi.00054.2005

Lv, F., Li, N., Kong, M., Wu, J., Fan, Z., Miao, D., et al. (2020). CDKN2a/p16 antagonizes hepatic stellate cell activation and liver fibrosis by modulating ROS levels. Front. Cell Dev. Biol. 8:176. doi: 10.3389/fcell.2020.00176

Mao, L., Liu, L., Zhang, T., Qin, H., Wu, X., and Xu, Y. (2020). Histone deacetylase 11 contributes to renal fibrosis by repressing KLF15 transcription. Front. Cell Dev. Biol. 8:235. doi: 10.3389/fcell.2020.00235

Martin, G. S., Mannino, D. M., Eaton, S., and Moss, M. (2003). The epidemiology of sepsis in the United States from 1979 through 2000. N. Engl. J. Med. 348, 1546-1554. doi: 10.1056/NEJMoa022139

Napolitano, M. A., Cipollaro, M., Cascino, A., Melone, M. A., Giordano, A., and Galderisi, U. (2007). Brg1 chromatin remodeling factor is involved in cell growth arrest, apoptosis and senescence of rat mesenchymal stem cells. J. Cell Sci. 120(Pt 16), 2904-2911. doi: 10.1242/jcs.004002

Nath, B., Levin, I., Csak, T., Petrasek, J., Mueller, C., Kodys, K., et al. (2011). Hepatocyte-specific hypoxia-inducible factor-1alpha is a determinant of lipid accumulation and liver injury in alcohol-induced steatosis in mice. Hepatology 53, 1526-1537. doi: 10.1002/hep.24256

Nowak, M., Gaines, G. C., Rosenberg, J., Minter, R., Bahjat, F. R., Rectenwald, J., et al. (2000). LPS-induced liver injury in D-galactosamine-sensitized mice requires secreted TNF-alpha and the TNF-p55 receptor. Am. J. Physiol. Regul. Integr. Comp. Physiol. 278, R1202-9. doi: 10.1152/ajpregu.2000.278.5.R1202
Oishi, Y., Spann, N. J., Link, V. M., Muse, E. D., Strid, T., Edillor, C., et al. (2017). SREBP1 contributes to resolution of pro-inflammatory TLR4 signaling by reprogramming fatty acid metabolism. Cell Metab. 25, 412-427. doi: 10.1016/ j.cmet.2016.11.009

Park, B. S., and Lee, J. O. (2013). Recognition of lipopolysaccharide pattern by TLR4 complexes. Exp. Mol. Med. 45:e66. doi: 10.1038/emm.2013.97

Raab, J. R., Runge, J. S., Spear, C. C., and Magnuson, T. (2017). Co-regulation of transcription by BRG1 and BRM, two mutually exclusive SWI/SNF ATPase subunits. Epigenetics Chromatin 10:62. doi: 10.1186/s13072-017-0167-8

Ramirez-Carrozzi, V. R., Nazarian, A. A., Li, C. C., Gore, S. L., Sridharan, R., Imbalzano, A. N., et al. (2006). Selective and antagonistic functions of SWI/SNF and $\mathrm{Mi}$-2beta nucleosome remodeling complexes during an inflammatory response. Genes Dev. 20, 282-296. doi: 10.1101/gad.1383206

Roychowdhury, S., Chiang, D. J., McMullen, M. R., and Nagy, L. E. (2014). Moderate, chronic ethanol feeding exacerbates carbon-tetrachloride-induced hepatic fibrosis via hepatocyte-specific hypoxia inducible factor 1alpha. Pharmacol. Res. Perspect. 2:e00061. doi: 10.1002/prp2.61

Sander, L. E., Sackett, S. D., Dierssen, U., Beraza, N., Linke, R. P., Muller, M., et al. (2010). Hepatic acute-phase proteins control innate immune responses during infection by promoting myeloid-derived suppressor cell function. J. Exp. Med. 207, 1453-1464. doi: 10.1084/jem.20091474

Schodel, J., Oikonomopoulos, S., Ragoussis, J., Pugh, C. W., Ratcliffe, P. J., and Mole, D. R. (2011). High-resolution genome-wide mapping of HIF-binding sites by ChIP-seq. Blood 117, e207-17. doi: 10.1182/blood-2010-10-314427

Singer, M., Deutschman, C. S., Seymour, C. W., Shankar-Hari, M., Annane, D., Bauer, M., et al. (2016). The third international consensus definitions for sepsis and septic shock (Sepsis-3). JAMA 315, 801-810. doi: 10.1001/jama.2016.0287

Smythies, J. A., Sun, M., Masson, N., Salama, R., Simpson, P. D., Murray, E., et al. (2019). Inherent DNA-binding specificities of the HIF-1alpha and HIF-2alpha transcription factors in chromatin. EMBO Rep. 20:e46401. doi: 10.15252/embr. 201846401

Sparkenbaugh, E. M., Saini, Y., Greenwood, K. K., LaPres, J. J., Luyendyk, J. P., Copple, B. L., et al. (2011). The role of hypoxia-inducible factor-1alpha in acetaminophen hepatotoxicity. J. Pharmacol. Exp. Ther. 338, 492-502. doi: 10.1124/jpet.111.180521

Sun, J., Wen, Y., Zhou, Y., Jiang, Y., Chen, Y., Zhang, H., et al. (2018). p53 attenuates acetaminophen-induced hepatotoxicity by regulating drugmetabolizing enzymes and transporter expression. Cell Death Dis. 9:536. doi: 10.1038/s41419-018-0507-z

Sun, L., Chen, B., Wu, J., Jiang, C., Fan, Z., Feng, Y., et al. (2020). Epigenetic regulation of a disintegrin and metalloproteinase (ADAM) promotes colorectal cancer cell migration and invasion. Front. Cell Dev. Biol. 8:581692. doi: 10.3389/ fcell.2020.581692

Traeger, T., Mikulcak, M., Eipel, C., Abshagen, K., Diedrich, S., Heidecke, C. D., et al. (2010). Kupffer cell depletion reduces hepatic inflammation and apoptosis but decreases survival in abdominal sepsis. Eur. J. Gastroenterol. Hepatol. 22, 1039-1049. doi: 10.1097/MEG.0b013e32833847db

Wang, B., Kaufmann, B., Engleitner, T., Lu, M., Mogler, C., Olsavszky, V., et al. (2019). Brg1 promotes liver regeneration after partial hepatectomy via regulation of cell cycle. Sci. Rep. 9:2320. doi: 10.1038/s41598-019-38568-w

Wang, H., Kouri, G., and Wollheim, C. B. (2005). ER stress and SREBP-1 activation are implicated in beta-cell glucolipotoxicity. J. Cell Sci. 118(Pt 17), 3905-3915. doi: $10.1242 /$ jcs. 02513

Wang, H. E., Jones, A. R., and Donnelly, J. P. (2017). Revised national estimates of emergency department visits for sepsis in the United States. Crit. Care Med. 45, 1443-1449. doi: 10.1097/CCM.0000000000002538

Wang, Y., Singh, R., Lefkowitch, J. H., Rigoli, R. M., and Czaja, M. J. (2006). Tumor necrosis factor-induced toxic liver injury results from JNK2-dependent activation of caspase-8 and the mitochondrial death pathway. J. Biol. Chem. 281, 15258-15267. doi: 10.1074/jbc.M512953200

Waseem, N., Limketkai, B. N., Kim, B., Woreta, T., Gurakar, A., and Chen, P. H. (2018). Risk and prognosis of acute liver injury among hospitalized patients with hemodynamic instability: a nationwide analysis. Ann. Hepatol. 17, 119-124. doi: 10.5604/01.3001.0010.7543

Wesche-Soldato, D. E., Chung, C. S., Gregory, S. H., Salazar-Mather, T. P., Ayala, C. A., and Ayala, A. (2007). CD8+ T cells promote inflammation and apoptosis in the liver after sepsis: role of Fas-FasL. Am. J. Pathol. 171, 87-96. doi: 10.2353/ ajpath.2007.061099 
Wu, Q., Sharma, S., Cui, H., LeBlanc, S. E., Zhang, H., Muthuswami, R., et al. (2016). Targeting the chromatin remodeling enzyme BRG1 increases the efficacy of chemotherapy drugs in breast cancer cells. Oncotarget 7, 2715827175. doi: 10.18632 /oncotarget.8384

Wu, T., Wang, H., Xin, X., Yang, J., Hou, Y., Fang, M., et al. (2020). An MRTF-ASp1-PDE5 axis mediates angiotensin-II-induced cardiomyocyte hypertrophy. Front. Cell Dev. Biol. 8:839. doi: 10.3389/fcell.2020.00839

Yan, J., and Li, S. (2014). The role of the liver in sepsis. Int. Rev. Immunol. 33, 498-510. doi: 10.3109/08830185.2014.889129

Yang, Y., Li, Z., Guo, J., and Xu, Y. (2020). Deacetylation of MRTF-A by SIRT1 defies senescence induced down-regulation of collagen type I in fibroblast cells. Biochim. Biophys. Acta Mol. Basis Dis. 1866:165723. doi: 10.1016/j.bbadis.2020. 165723

Yang, Y., Liu, L., Fang, M., Bai, H., and Xu, Y. (2019a). The chromatin remodeling protein BRM regulates the transcription of tight junction proteins: implication in breast cancer metastasis. Biochim. Biophys. Acta Gene Regul. Mech. 1862, 547-556. doi: 10.1016/j.bbagrm.2019.03.002

Yang, Y., Liu, L., Li, M., Cheng, X., Fang, M., Zeng, Q., et al. (2019b). The chromatin remodeling protein BRG1 links ELOVL3 trans-activation to prostate cancer metastasis. Biochim. Biophys. Acta Gene Regul. Mech. 1862, 834-845. doi: 10.1016/j.bbagrm.2019.05.005

Zhang, C., Shin, D. J., and Osborne, T. F. (2005). A simple promoter containing two Sp1 sites controls the expression of sterol-regulatory-element-binding protein 1a (SREBP-1a). Biochem. J. 386(Pt 1), 161-168. doi: 10.1042/BJ20041514
Zhang, Y., Yuan, Y., Li, Z., Chen, H., Fang, M., Xiao, P., et al. (2019). An interaction between BRG1 and histone modifying enzymes mediates lipopolysaccharide-induced proinflammatory cytokines in vascular endothelial cells. J. Cell. Biochem. 120, 13216-13225. doi: $10.1002 /$ jcb. 28595

Zhao, Q., Yang, J., Chen, H., Li, J., Que, L., Zhu, G., et al. (2019). Peli1 induction impairs cardiac microvascular endothelium through Hsp90 dissociation from IRE1alpha. Biochim. Biophys. Acta Mol. Basis Dis. 1865, 2606-2617. doi: 10. 1016/j.bbadis.2019.06.017

Zhu, W., Bao, R., Fan, X., Tao, T., Zhu, J., Wang, J., et al. (2013). PD-L1 blockade attenuated sepsis-induced liver injury in a mouse cecal ligation and puncture model. Mediators Inflamm. 2013:361501. doi: $10.1155 / 2013 / 361501$

Conflict of Interest: The authors declare that the research was conducted in the absence of any commercial or financial relationships that could be construed as a potential conflict of interest.

Copyright $\odot 2021$ Dong, Zhu, Zhang, Fan, Zhang, Fan and Xu. This is an open-access article distributed under the terms of the Creative Commons Attribution License $(C C B Y)$. The use, distribution or reproduction in other forums is permitted, provided the original author(s) and the copyright owner(s) are credited and that the original publication in this journal is cited, in accordance with accepted academic practice. No use, distribution or reproduction is permitted which does not comply with these terms. 